\title{
The Humoral and Cellular Immune Response Characteristic of Propolis Flavonoid Used as Adjuvant to Inactivated PPV Vaccine in Sows \\ Xia Ma1,2, Zhenhuan Guo ${ }^{2}$, Yonglu Liu', Yanzhou Zhou ${ }^{1}$, Xiaolin Wang ${ }^{1}$, Zhiqiang Shen ${ }^{2 *}$ and Jinliang Wang ${ }^{2}$ \\ ${ }^{1}$ Medicinal Engineering Department of Henan University of Animal Husbandry and Economy, Zhengzhou, P.R. China \\ ${ }^{2}$ Binzhou Animal Science and Veterinary Medicine Academy of Shandong Province, P.R. China
}

\begin{abstract}
The present study was conducted to assess the effects of propolis flavonoid used as adjuvant on the immune response of Landrace-Yorkshire hybrid sows immunized with an inactivated vaccine of porcine parvovirus (PPV). Thirty Landrace-Yorkshire hybrid sows were randomly assigned to one of 3 groups, and the sows in two adjuvant groups were intramuscular injected PPV vaccine with $2.0 \mathrm{~mL}$ propolis flavonoid adjuvant (PA) or oilemulsion adjuvant $(\mathrm{OA})$, respectively. After that, serum hemagglutination inhibition antibody titers, specific IgM, IgA and IgG subclasses were measured to estimate the humoral immunity for the adjuvant effects of propolis flavonoid, as well as peripheral lymphopoiesis activity, and lymphocyte factor concentrations of Th1 and Th2 for cellular immune responses. Results indicated in a significant enhancing effect of PA on concentrations of IgM, IgG2, IgG3, IL-2 and IFN- $y$ comparing to OA. Especially in improving the effect of Th1 cellular immune response, the PA was superior to OA. These findings suggested that PA can significantly enhance the immune responses against PPV vaccine and could be exploited to a new PPV vaccine in sows.
\end{abstract}

Keywords: Propolis flavonoid; Porcine parvovirus; Immunological adjuvant; Humoral immune response; Cellular immune response.

\section{Introduction}

Propolis, applied as a traditional cure in folk medicine empirically for centuries, is a mix ingredients composeed by honeybees with various plant resinous and mandibular gland secretion [1]. It is well known for latent health benefit and is reported to own valuable biological activities, including antivirus, immune enhancement, antibiosis, antioxidation, hepatoprotection, anticancer, anti-fatigue, and so on [2-4]. It is an splendid immune system booster and natural antibiotic with no sideeffect. In recent years, propolis has become an issue of increasing interest in the investigators for its versatile biological activities and broadly exchanged by the pharmaceutical industries as the health-food and an alternative medicine in various parts of the world.

Propolis flavonoid (PF) is a kind of ingredients extracted from propolis and has been used as a harmless natural adjuvant in chickens vaccinated with activated vaccine, and the results showed that PF could remarkably improve the immune activity in the cellular and humoral immune response [2,4]. But the adjuvant effects and feature PF on inactivated vaccine to sows had not be considered detailedly in humoral and cellular immunity response.

Recently, the animal viral infectious diseases, such as severe untypical classical swine fever, acute respiratory syndrome, cow transmissible spongiform encephalopathy, swine hyperpyrexia disease and so on are worldwide concerned as they made a stage of comeback with emerge continuously and spread quickly, and constantly cause a enormous loss in domestic animal and poultry industry [5]. PPV could cause reproductive failure in pregnant sows, which is characterized by stillbirths, fetal and embryonic death, mummification and delayed return to oestrus [6]. Although the acute infection of postnatal and non-pregnant pigs is often sub-clinical, PPV has been linked to skin lesion occurrence in piglets [7], non-suppurative myocarditis in lactating piglets and interstitial nephritis in slaughter aged pigs [8].

Several research results have pointed out that vaccination is the effective method for controlling viral disease $[9,10]$. The ideal and successful vaccination depends on the association with antigen and potent adjuvant which can increase the immune effect of vaccine. A desired adjuvant could not only start specific effectors of the immune system to strengthen the cellular and/or humoral immune responses against that antigen, but also activate auxiliary or cytotoxic $\mathrm{T}$ cells $[8,11,12]$. On the other hand, better adjuvant should have no or lower toxicity and side effects [13]. But there are many deficiencies in commonly used adjuvant, for instance, oilemulsion adjuvant (OA) can cause induration or necrosis in the local, acute inflammation and disseminated granulomas in lungs, lymph nodes and skeletal muscles in rats or rabbits [14]. Therefore, it is urgent to explore a new adjuvant with high humoral and cellular immunity efficacy and security.

Our previous studies demonstrated that PF possessed a better immunological enhancement on cellular and humoral immunity in model animal of guinea pig inactivated PPV vaccine [15]. In this study, the authors determined the effects of PF on serum antibody tiers, immunoglobulin (Ig)M, IgA and IgG subclass for humoral immunity, and peripheral lymphopoiesis and lymphocyte excretion of Th1 cytokine (interleukin (IL)-2 and interferon (IFN)- $\gamma$ ) and Th2 cytokine (IL-4, IL-6, IL-10 and IL-12) for cellular immunity of pigs vaccinated with inactivated PPV vaccine compared with OA. Thus, the aim of this study was to observe the adjuvant effect and characteristic of PF on immune response of immunized sows and offer theoretical evidence for developing PF into PPV vaccine adjuvant.

*Corresponding author: Zhiqiang Shen, Binzhou Animal Science and Veterinary Medicine Academy of Shandong Province, No.169 Huanghe 2nd Road, Binzhou, Shnadong 256600, P.R. China, Tel: +86-543-3405108; Fax: +86-543-3252652; E-mail: bzshenshi@126.com

Received: December 12, 2015; Accepted: January 25, 2016; Published February 28, 2016

Citation: Ma X, Guo Z, Liu Y, Zhou Y, Wang X, et al. (2016) The Humoral and Cellular Immune Response Characteristic of Propolis Flavonoid Used as Adjuvant to Inactivated PPV Vaccine in Sows. Biochem Anal Biochem 5: 242. doi:10.4172/2161-1009.1000242

Copyright: (c) $2016 \mathrm{Ma} \mathrm{X}$, et al. This is an open-access article distributed under the terms of the Creative Commons Attribution License, which permits unrestricted use, distribution, and reproduction in any medium, provided the original author and source are credited. 
Citation: Ma X, Guo Z, Liu Y, Zhou Y, Wang X, et al. (2016) The Humoral and Cellular Immune Response Characteristic of Propolis Flavonoid Used as Adjuvant to Inactivated PPV Vaccine in Sows. Biochem Anal Biochem 5: 242. doi:10.4172/2161-1009.1000242

Page 2 of 5

\section{Materials and Methods}

\section{Preparation of adjuvant and vaccine}

Propolis was purchased from Shandong province Qingkun Beeswax honeycomb processing factory. PF was prepared in our laboratory in a final purity of $925 \mathrm{mg} \cdot \mathrm{g}^{-1}$. The PF adjuvant (PA) was prepared as previoulsy described [16]. The PF was dissolved with phosphate buffer solution (PBS, pH 6.2) in a final concentration of $40 \mathrm{mg} \cdot \mathrm{mL}^{-1}$. PPV, the virus contained 2048 haemagglutination units (HAU) $\cdot \mathrm{mL}^{-1}$, was obtained from China Institute of Veterinary Drug Control. The adjuvant vaccines containing PA or OA were prepared by Lvdu Veterinary Biologicals Co. Ltd., Binzhou, China. Their virus antigen contents were the same.

\section{Main reagents}

RPMI-1640 (Gibco) supplemented with streptomycin $100 \mathrm{IU} \cdot \mathrm{mL}^{-1}$, benzylpenicillin $100 \mathrm{IU} \cdot \mathrm{mL}^{-1}$ and $10 \%$ fetal bovine serum (FBS), was used for re-suspending and washing the cells, culturing and dilutingthe mitogen the cells. The mitogen of concanavalin A (ConA, Sigma) was dissolved with $0.1 \mathrm{mg} \cdot \mathrm{mL}^{-1}$ RPMI-1640. Sodium heparin was dissolved with $5 \mathrm{mg} \cdot \mathrm{mL}^{-1}$ of PBS. The 3-(4,5-dimethylthiazol-2-yl)-2,5diphenyltetrazolium bromide (MTT, Amresco Co.) was dissolved into 5 $\mathrm{mg} \cdot \mathrm{mL}^{-1}$ with calcium and magnesium free (CMF) PBS ( $\mathrm{pH}$ 7.4). These reagents were all filtered through a $0.22 \mu \mathrm{m}$ syringe filter. Dimethyl sulfoxide (DMSO) was purchased from Shanghai Lingfeng Chemical Reagent Ltd. Lymphocytes separation medium was purchased from Tianjing Haoyang Biological Manufacture co. Ltd. The enzyme-linked immunosorbent assay (ELISA) kits for IgM, IgA, IgG1, IgG2, IgG3, IgG4, IL-2, IFN- $\gamma$, IL-4, IL-6, IL-10 and IL-12 were purchased from R\&D Systems Inc., Minneapolis, USA.

\section{Animals, housing and treatment}

Thirty Landrace-Yorkshire hybrid sows (aged from 198 to 204, and average weight is $64.5 \mathrm{~kg}$ ) were randomly assigned to one of 3 groups, receiving intramuscular injection of PPV vaccine with $2.0 \mathrm{~mL}$ PA, OA or physiological saline (blank control group, BC group), respectively. The animals were kept in ten pigpens divide equally under standard conditions in the Experimental Animal Center of Shandong province Animal Science and Veterinary Medicine Academy of Binzhou, ( NO. SYXK (lu) 20110066 ). They were maintained in an air-conditioned room with light from $06: 00 \mathrm{~h}$ to $18: 00 \mathrm{~h}$. The room temperature (24 $\pm 3^{\circ} \mathrm{C}$ ) and humidity were controlled automatically. They were fed water and food ad libitum. All the experiment animals of procedures and their care conformed to the internationally accepted principles as found by the government of China for the Guidelines for Keeping Experimental Animals issued. The antibody against PPV was negative before the experiment.

On days 7, 14,21, 28, 35 and 42 after vaccination, the blood of 6 sows randomly from each group were sampled for measuring PPV serum hemagglutination inhibition (HI) antibody titer by micro-method, $\operatorname{IgM}, \operatorname{IgA}$ and $\operatorname{IgG}$ subclasses with method of ELISA kit dynamically and continuously. On days 7, 14, 21, 28, 35 and 42 after vaccination, the peripheral blood of 4 pigs randomly from each group were sampled for examination of lymphocyte proliferation by MTT assay [17] and analyzing lymphocyte cytokine of IL-2, IFN- $\gamma$, IL-4, IL-6, IL-10 and IL-12 by ELISA kit [16].

\section{Statistical analysis}

Data are expressed as the mean \pm S.D. LSD's and Duncan multiple range test was used to determine the differences among groups. P-values of less than 0.05 were considered statistically significant.

\section{Result}

\section{The serum variation antibody titer}

The serum dynamic variation $\mathrm{HI}$ antibody titers of each group are demonstrated in Table 1. The HI antibody titers in PA and OA vaccination groups improved significantly $(p<0.05)$ from days 7 to 42 compared with the BC group. On days 7 and 14 after vaccination, the $\mathrm{HI}$ antibody titers in PA group were higher than OA group $(p>0.05)$. On days $21,28,35$ and 42 , the HI antibody titers in group PA were lower significantly than those of group OA $(p<0.05)$.

\section{The serum variation of IgM and IgA content}

The serum variation of IgM content of every group is illustrated in Figure $1 \mathrm{~A}$. On days 7 and 21 after vaccination, IgM content of PA group was higher than that of OA group $(p<0.05)$, while on days $14,28,35$ and 42 after vaccination, IgM content of PA group only was numerically higher $(p>0.05)$ than that of OA group, and higher significantly $(p<0.05)$ than that of $\mathrm{BC}$ group.

The serum variation of IgA content of every group is shown in Figure 1B. From 7 to 42 after immunization, the IgA content in group $\mathrm{PA}, \mathrm{OA}$ and $\mathrm{BC}$ had no significant $((p>0.05)$.

\section{The serum variation of IgG subclasses content}

The serum variation of IgG1 content of every group is illustrated in Figure 2A. The IgG1 content in PA and $\mathrm{OA}$ adjuvant groups was higher significantly $(p<0.05)$ than that of $\mathrm{BC}$ group from 14 to 35 after vaccination. On day 7 after vaccination, IgG1 content of PA group was higher $(p>0.05)$ than that of OA group. But on 21 and 28 , the IgG1 content in OA adjuvant group was higher significantly $(p<0.05)$ than that of PA group.

\begin{tabular}{|c|c|c|c|c|c|c|}
\hline Group & $\mathbf{D}_{\mathbf{7}}$ & $\mathbf{D}_{14}$ & $\mathbf{D}_{21}$ & $\mathbf{D}_{28}$ & $\mathbf{D}_{35}$ & $\mathbf{D}_{42}$ \\
\hline PA & $4.5 \pm 0.4^{\mathrm{a}}$ & $7.4 \pm 0.5^{\mathrm{a}}$ & $7.5 \pm 0.4^{\mathrm{b}}$ & $7.8 \pm 0.7^{\mathrm{b}}$ & $7.3 \pm 0.5^{\mathrm{b}}$ & $6.5 \pm 0.5^{\mathrm{b}}$ \\
\hline OA & $4.3 \pm 0.5^{\mathrm{a}}$ & $7.3 \pm 0.5^{\mathrm{a}}$ & $8.5 \pm 0.6^{\mathrm{a}}$ & $8.8 \pm 0.5^{\mathrm{a}}$ & $8.3 \pm 0.7^{\mathrm{a}}$ & $7.5 \pm 0.7^{\mathrm{a}}$ \\
\hline BC & $0 \pm 0^{\mathrm{b}}$ & $0 \pm 0^{\mathrm{b}}$ & $0 \pm 0^{\mathrm{c}}$ & $0 \pm 0^{\mathrm{c}}$ & $0 \pm 0^{\mathrm{c}}$ & $0 \pm 0^{\mathrm{c}}$ \\
\hline
\end{tabular}

PA: Propolis Adjuvant; OA: Oilemulsion Adjuvant; BC: Blank Control; The same as follows.

Data within a column without the same superscripts (a-c) differ significantly $(p<0.05)$.

Table 1: The dynamic variation of $\mathrm{HI}$ antibody titer after vaccination $\left(\log _{2}\right)$.

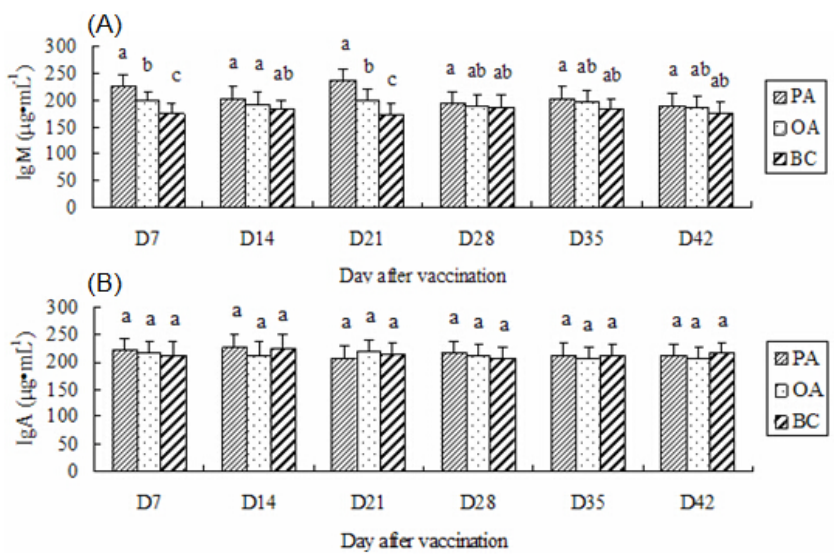

Figure 1: The dynamic changes of $\lg M$ and $\lg A$ content after vaccination $\left(\mu \mathrm{g} \cdot \mathrm{mL}^{-1}\right) .{ }^{\mathrm{a}-\mathrm{c}}$ Bars in the same day without the same superscripts differ significantly $(p<0.05)$. 
Citation: Ma X, Guo Z, Liu Y, Zhou Y, Wang X, et al. (2016) The Humoral and Cellular Immune Response Characteristic of Propolis Flavonoid Used as Adjuvant to Inactivated PPV Vaccine in Sows. Biochem Anal Biochem 5: 242. doi:10.4172/2161-1009.1000242

The serum variation of IgG2 content of every group is shown in Figure $2 \mathrm{~B}$. The IgG2 content in $\mathrm{PA}$ and $\mathrm{OA}$ adjuvant groups was higher significantly $(p<0.05)$ than that of BC group from 7 to 28 after vaccination. On day 14 and 21 after vaccination, IgG2 content of PA group was higher significantly $(p<0.05)$ than that of OA group.

The serum variation of IgG3 content of every group is illustrated in Figure 2C. The IgG3 content in PA and OA adjuvant groups was higher significantly $(p<0.05)$ than that of BC group from 7 to 35 after vaccination. On day 7 and 14 after vaccination, IgG3 content of PA group was higher significantly $(p<0.05)$ than that of OA group.

The serum variation of IgG4 content of every group is shown in Figure 2D. The IgG4 content in $\mathrm{OA}$ adjuvant group was higher significantly $(p<0.05)$ than that of BC group on day 7 and 21 after vaccination. From 7 to 42 after vaccination, the IgG4 content of PA group was lower $(p>0.05)$ than that of OA group.

\section{Peripheral lymphocyte proliferation activity}

The lymphocyte proliferation activities are shown in Table 2. The $A_{570}$ values of PA group were significantly bigger than those of the $\mathrm{OA}$ and $\mathrm{BC}$ groups from days 7 to 28 after vaccination significantly
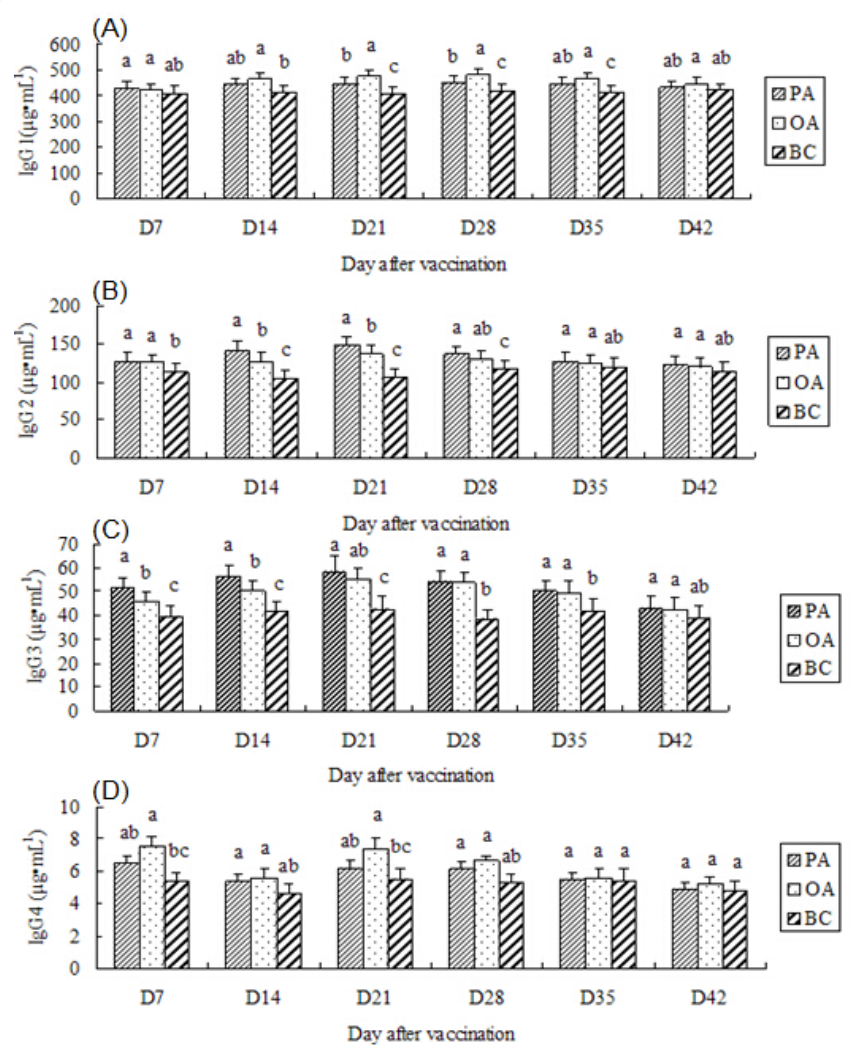

Figure 2: The changes of IgG1, IgG2, IgG3 and IgG4 content after vaccination $\left(\mu \mathrm{g} \cdot \mathrm{mL}^{-1}\right)$. ${ }^{\mathrm{a}-\mathrm{c}}$ Bars in the same day without the same superscripts differ significantly $(p<0.05)$.

\begin{tabular}{|c|c|c|c|c|c|c|}
\hline Group & $\mathbf{D}_{\mathbf{7}}$ & $\mathbf{D}_{14}$ & $\mathbf{D}_{21}$ & $\mathbf{D}_{28}$ & $\mathbf{D}_{35}$ & $\mathbf{D}_{42}$ \\
\hline PA & $0.36 \pm 0.02^{\mathrm{a}}$ & $0.33 \pm 0.01^{\mathrm{a}}$ & $0.37 \pm 0.02^{\mathrm{a}}$ & $0.30 \pm 0.01^{\mathrm{a}}$ & $0.29 \pm 0.01^{\mathrm{a}}$ & $0.28 \pm 0.01^{\mathrm{a}}$ \\
\hline OA & $0.32 \pm 0.01^{\mathrm{b}}$ & $0.29 \pm 0.02^{\mathrm{b}}$ & $0.34 \pm 0.02^{\mathrm{b}}$ & $0.27 \pm 0.02^{\mathrm{b}}$ & $0.28 \pm 0.02^{\mathrm{a}}$ & $0.29 \pm 0.02^{\mathrm{a}}$ \\
\hline BC & $0.29 \pm 0.02^{\mathrm{c}}$ & $0.28 \pm 0.01^{\mathrm{b}}$ & $0.30 \pm 0.01^{\mathrm{c}}$ & $0.26 \pm 0.02^{\mathrm{b}}$ & $0.27 \pm 0.02^{\mathrm{a}}$ & $0.27 \pm 0.01^{\mathrm{a}}$ \\
\hline Data within a column without the same superscripts a-c differ significantly $(p<0.05)$. \\
Table 2: The changes in lymphocyte proliferation of blood $\left(A_{570}\right.$ value $)$.
\end{tabular}

$(p<0.05)$. On day 7 and 21 after vaccination, the $A_{570}$ values in OA group were bigger significantly $(p<0.05)$ than that of $\mathrm{BC}$ group.

\section{Th1 cytokine level}

Th1 cytokine of IL- 2 content is listed as Figure 3A. The IL-2 content in PA group was significantly higher $(p<0.05)$ than those of $\mathrm{OA}$ and BC groups from 7 to 42 after vaccination. And on day 7 and 21 after vaccination, IL-2 content of OA group was higher significantly $(p<0.05)$ than that of BC group.

Th1 cytokine of IFN- $\gamma$ content is listed as Figure 3B. PA triggered stronger IFN- $\gamma$ content significantly $(p<0.05)$ than the OA group from 7 to 42 after vaccination.

\section{Th2 cytokine level}

Th2 cytokine of IL- 4 content is shown in Figure 4A. The IL-4 content in PA group was significantly lower $(p<0.05)$ than that of OA group from 7 to 42 after vaccination. And on day 7 and 21 after vaccination, IL- 4 content in PA group was significantly lower $(p<0.05)$ than that of BC group.

Th2 cytokine of IL- 6 content is shown in Figure 4B. The IL-6 content in PA group was lower $(p>0.05)$ than that of OA group from 7 to 42 after vaccination.

Th2 cytokine of IL-10 content is illustrated in Figure 4C. The IL-10 content in PA group was significantly lower $(p<0.05)$ than those of OA and $\mathrm{BC}$ groups from 7 to 28 after vaccination.

Th2 cytokine of IL-12 content is illustrated in Figure 4D. The IL-12 content in PA group was lower $(p>0.05)$ than that of OA group from 7 to 42 after vaccination.

\section{Discussion}

The combinations of adjuvant may combine multiple adjuvant components to achieve the desired mix of immune responses. During early period ( $7 \mathrm{~d}$ ) of vaccination, our studies suggested that the serum $\mathrm{HI}$ antibody titer against PPV and IgM content of group PA were higher than that of group OA, which suggested that the PA was superior to the $\mathrm{OA}$ in the early vaccination. This could get the immuned animals more effectively on resisting wild virus infection. In mice model, Orsatti also verified that propolis could start the initial steps of the immune response [18].
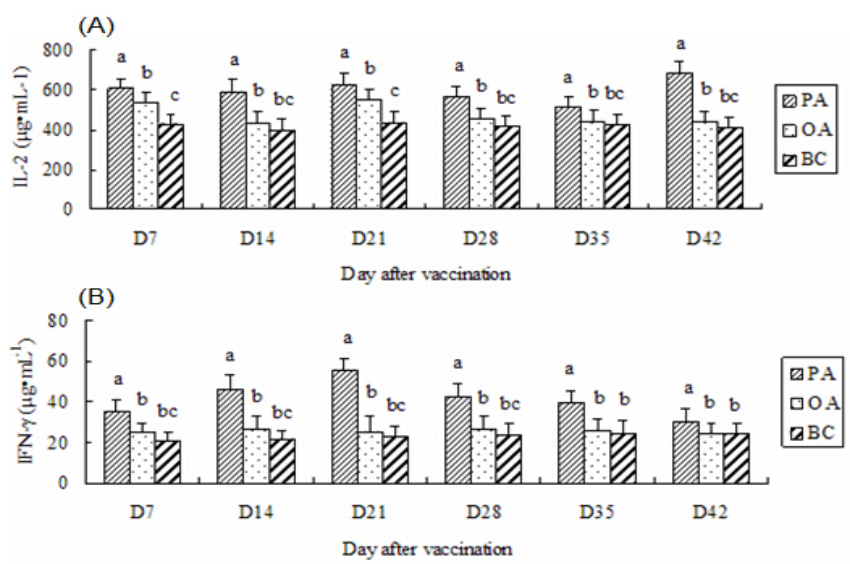

Figure 3: The dynamic changes of IL-2 and IFN-y content after vaccination $\left(\mu \mathrm{g} \cdot \mathrm{mL}^{-1}\right)$. a-c Bars in the same day without the same superscripts differ significantly $(p<0.05)$. 

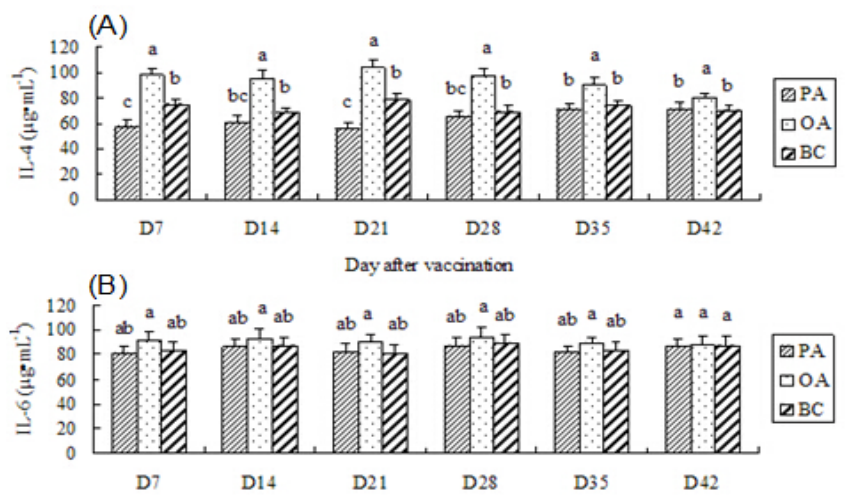

(C)

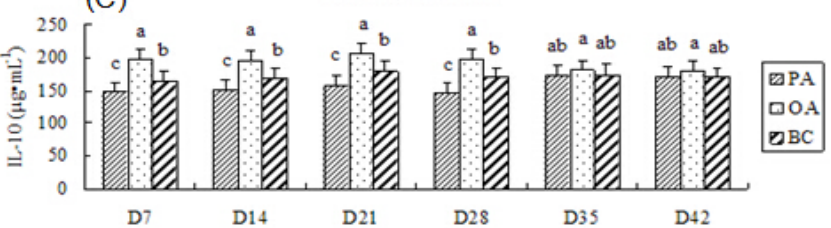

(D)

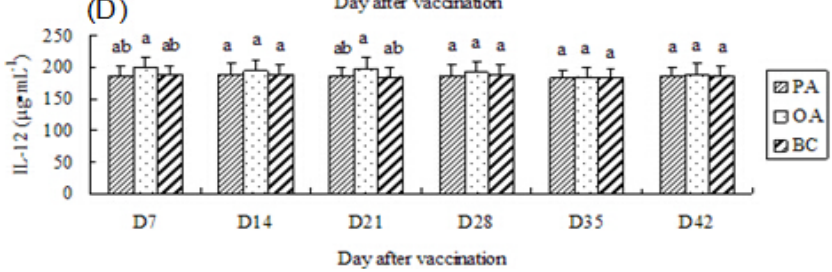

Figure 4: The changes of IL-4, IL-6, IL-10 and IL-12 content after vaccination $\left(\mu \mathrm{g} \cdot \mathrm{mL}^{-1}\right) .{ }^{\mathrm{a}-\mathrm{c}}$ Bars in the same day without the same superscripts differ significantly $(p<0.05)$.

There are different subclasses of IgG in serum such as IgG1, IgG2, IgG3 and IgG4 that afford the bulk of immunity to most infectious disease. Raised antibody titers are very important for microbial killing by way of antibody-mediated mechanisms. Our data showed that IgG2 and IgG3 contents were significantly higher in the sows immunized with PA than that of immunized with $\mathrm{OA}$, indicating that PF acts synergistically to promote the IgG subclasses production. Sforcin also concluded that PF stimulates antibody production [19]. And studies in the animal models have shown that antibodies play a significant role in the immune system to defense against PPV [19-22].

$\mathrm{PF}$ enhances immune responses in various ways such as formation of the immunostimulating complex, activation of helper and cytotoxic $\mathrm{T}$ cells. In addition to activating the humoral immune response, PF also increased cellular immune responses [23,24]. In this study, PF was various in regards to their adjuvant effects on the immune responses stimulated the T lymphocyte cells to secrete cytokines. As shown in Figure $3 \mathrm{~A}$ and $3 \mathrm{~B}, \mathrm{PF}$ could significantly increased the production of Th1 cytokines IL- 2 and IFN- $\gamma$, which suggested that PF simultaneously elicited a Th1 immune response. These findings are consistent with Blonska's study which demonstrated that PF could improve the activity of T lymphocyte, increase the secretion of some cytokines, such as IL-2 and TNF- $\alpha$, thus enhance immune function of organism [25].

Th1 immune activation contributes to cell-mediated immunity whereas Th2 immune activation favours the humoral immune response [26]. Th1/Th2 balance is a prerequisite for the functionality of immune system against infections. The immunomodulatory of PF has been widely investigated lately, both in vivo and in vitro [27]. PF has been advised to be used as a promising adjuvant material on duck inactivated vaccines [28]. Important functional properties of immune cells are their capability to synthesize and secrete soluble polypeptide factors referred to as cytokines. Most secreted cytokines are bind to specific receptors on the surface of target cells. Upon binding they act to regulate differentiation, growth and/or to optimize the immune response [29]. Using a Polish sample, Ansorge reported that propolis had immunoregulatory effects that might be regulated by Erk2 MAPK signals that improve cellular growth [30]. In T cell dependent immune response, the specific antibody produce need a progressive change in the predominant immunoglobulin class, which is adjusted by $\mathrm{T}$ cells and their cytokines. IL- 4 and IL-10 preferentially switches activated B cells to the IgG1 isotype (Th2 type immune response), IL-2 and IFN- $\gamma$ enhances IgG2 and IgG3 responses (Th1 type immune response) [31].

\section{Conclusions}

PF significantly increased the serum levels of $\operatorname{IgM}$ and $\operatorname{IgG} 2 / 3$, as well as T lymphocyte proliferation when administered in sows with an inactivated vaccine against PPV. The enhanced IgG subclasses levels paralleled the increased cytokine levels of IFN- $\gamma$ and IL-2. This adjuvant characteristic and activity was evident in both cellular and humoral immune responses, and PF could be exploited to a new PPV vaccine adjuvant in sows.

\section{Acknowledgements}

The project was jointly supported by Shandong Province National Natural Science Foundation (Grant No.Y2005D10) and Henan Province National Natural Science Foundation of Education Department (Grant No. 13A230383, 14A230012). The authors would like to grateful to all other staff in the experiments for their assistances.

\section{References}

1. Sforcin JM (2007) Propolis and the immune system: a review. J Ethnopharmacol 113: $1-14$

2. Fan $Y$, Ma L, Zhang W, Xu Y, Suolangzhaxi et al. (2014) Microemulsion can improve the immune-enhancing activity of propolis flavonoid on immunosuppression and immune response. Int J Biol Macromol 63: 126-132.

3. Yuqing Z, Zhan'ao S, Jiaguo L, Deyun W, Baokang Z, et al. (2012) Flavone ingredients can synergistically inhibit NDV infecting cell and improve ND vaccine's protective rate. Int J Biol Macromol 51: 201-208.

4. Fan YP, Hu YL, Wang DY, Guo ZH, Zhao XN, et al. (2010) Epimedium polysaccharide and propolis flavone can synergistically stimulate lymphocyte proliferation in vitro and enhance the immune responses to ND vaccine in chickens. Int J Biol Macromol 47: 87-92.

5. Kong X Hu Y, Rui R, Wang D, Li X (2004) Effects of Chinese herbal medicinal ingredients on peripheral lymphocyte proliferation and serum antibody titer after vaccination in chicken. Int Immunopharmacol 4: 975-982.

6. Mengeling WL (2006) Porcine parvovirus. In: Straw BE, Zimmerman JJ, D'Allaire S, Taylor DJ (eds.), Diseases of Swine, (9thedn.) Blackwell Publishing, Ames, IA.

7. Lager KM, Mengeling WL (1994) Porcine parvovirus associated with cutaneous lesions in piglets. J Vet Diagn Invest 6: 357-359.

8. Drolet R, D'Allaire S, Larochelle R, Magar R, Ribotta M, et al. (2002) Infectious agents identified in pigs with multifocal interstitial nephritis at slaughter. Vet Rec 150: 139-143.

9. Parke CR, Burgess GW (1993) An economic assessment of porcine parvovirus vaccination. Aust Vet J 70: 177-180.

10. Gardner IA, Carpenter TE, Leontides L, Parsons TD (1996) Financial evaluation of vaccination and testing alternatives for control of parvovirus-induced reproductive failure in swine. J Am Vet Med Assoc 208: 863-869.

11. Leclerc C (2003) New approaches in vaccine development. Comp Immunol Microbiol Infect Dis 26: 329-341.

12. Storni T, Kündig TM, Senti G, Johansen $P$ (2005) Immunity in response to particulate antigen-delivery systems. Adv Drug Deliv Rev 57: 333-355. 
Citation: Ma X, Guo Z, Liu Y, Zhou Y, Wang X, et al. (2016) The Humoral and Cellular Immune Response Characteristic of Propolis Flavonoid Used as Adjuvant to Inactivated PPV Vaccine in Sows. Biochem Anal Biochem 5: 242. doi:10.4172/2161-1009.1000242

Page 5 of 5

13. Aguilar JC, Rodríguez EG (2007) Vaccine adjuvants revisited. Vaccine 25: 3752-3762.

14. Holmdahl R, Lorentzen JC, Lu S, Olofsson P, Wester L, et al. (2001) Arthritis induced in rats with nonimmunogenic adjuvants as models for rheumatoid arthritis. Immunol Rev 184: 184-202.

15. Ma X, Guo Z, Shen Z, Wang J, Hu Y, et al. (2011) The immune enhancement of propolis adjuvant on inactivated porcine parvovirus vaccine in guinea pig. Cell Immunol 270: 13-18.

16. Paulino N, Scremin FM, Raichaski LB, Marcucci MC, Scremin A, et al. (2002) Mechanisms involved in the relaxant action of the ethanolic extract of propolis in the guinea-pig trachea in-vitro. J Pharm Pharmacol 54: 845-852.

17. Chen Y, Wang D, Hu Y, Guo Z, Wang J, et al. (2010) Astragalus polysaccharide and oxymatrine can synergistically improve the immune efficacy of Newcastle disease vaccine in chicken. Int J Biol Macromol 46: 425-428.

18. Orsatti CL, Missima F, Pagliarone AC, Bachiega TF, Búfalo MC, et al. (2010) Propolis immunomodulatory action in vivo on Toll-like receptors 2 and 4 expression and on pro-inflammatory cytokines production in mice. Phytother Res 24: 1141-1146.

19. Sforcin JM, Orsi RO, Bankova V (2005) Effect of propolis, some isolated compounds and its source plant on antibody production. J Ethnopharmacol 98: 301-305.

20. Molitor TW, Joo HS, Thacker BJ (1985) Potentiating effect of adjuvants on humoral immunity to porcine parvovirus vaccines in guinea pigs. Vet Microbiol 10: $209-218$

21. Pye D Bates J, Edwards SJ, Hollingworth J (1990) Development of a vaccine preventing parvovirus-induced reproductive failure in pigs. Aust Vet J 67: 179-182.

22. Paul PS, Mengeling WL (1986) Vaccination of swine with an inactivated porcine parvovirus vaccine in the presence of passive immunity. $J$ Vet Med Assoc 188: 410-413.

23. Fischer G, Paulino N, Marcucci MC, Siedler BS, Munhoz LS (2010) Memorias do Instituto Oswaldo Cruz, Green propolis phenolic compounds act as vaccine adjuvants, improving humoral and cellular responses in mice inoculated with inactivated vaccines. Rio. de Janeiro 105: 908-913.

24. Pagliarone AC, Missima F, Orsatti CL, Bachiega TF, Sforcin JM (2009) Propolis effect on Th1/Th2 cytokines production by acutely stressed mice. J Ethnopharmacol 125: 230-233.

25. Blonska M, Bronikowska J, Pietsz G, Czuba ZP, Scheller S, et al. (2004) Effects of ethanol extract of propolis (EEP) and its flavones on inducible gene expression in J774A.1 macrophages. J Ethnopharmacol 91: 25-30.

26. Das J, Chen CH, Yang L, Cohn L, Ray P, et al. (2001) A critical role for NF-kappa $B$ in GATA3 expression and TH2 differentiation in allergic airway inflammation. Nat Immunol 2: 45-50.

27. Fischer G, Cleff MB, Dummer LA, Paulino N, Paulino AS, et al. (2007) Adjuvant effect of green propolis on humoral immune response of bovines immunized with bovine herpesvirus type 5 . Vet Immunol Immunopathol 116: 79-84.

28. Cai JL, Tang XL, Yang LF, Su XY (2001) Propolis inactivated vaccine against infectious serositis in young ducks. Chin J Vet Sci 2: 552-553.

29. Sforcin JM, Orsi RO, Bankova V (2005) Effect of propolis, some isolated compounds and its source plant on antibody production. J Ethnopharmacol 98: 301-305

30. Ansorge S, Reinhold D, Lendeckel U (2003) Propolis and some of its constituents down-regulate DNA synthesis and inflammatory cytokine production but induce TGF-beta1 production of human immune cells. Z Naturforsch C 58: 580-589.

31. Roitt I, Brostoff J, Male D (2001) Immunology, 6th Mosby Publications, London. 